\title{
CLAVES DE LECTURA DEL APOCALIPSIS DE SAN JUAN
}

\section{KEYS FOR READING THE APOCALYPSE OF ST JOHN}

Flavio Gutiérrez Velasco*

\begin{abstract}
RESUMEN
Ante la proliferación de lecturas fundamentalistas del Apocalipsis de san Juan, que nos hacen ver el fin del mundo como algo inminente, el presente artículo propone algunas claves de lectura para interpretar adecuadamente el mensaje de este escrito tan polémico, como son, por ejemplo, la comprensión del género literario apocalíptico que pretendía fortalecer al pueblo cristiano perseguido durante las persecuciones de Diocleciano a fines del siglo I; o la misma estructura literaria del libro que tiene como eje el número siete. El presente escrito se sitúa, pues, en la línea de la teología de la historia, una visión de la historia de la iglesia perseguida por los romanos a fines del siglo primero.
\end{abstract}

\section{PALABRAS CLAVE:}

Apocalipsis, lenguaje cifrado, teología de la historia, interpretación

\begin{abstract}
This article proposes some reading keys to properly interpret the message of this controversial issue over the proliferation of fundamentalist readings of John's Apocalypse, where we see the end of the world as imminent, such as the understanding of the apocalyptic genre that intended to strengthen Christian people persecuted during the Diocletian's persecution in the late first century, or the same literary structure of the book that is focused on the number seven. Thus, this article is placed in line with the theology of history, an overview of the church history persecuted by the Romans in the late first century.
\end{abstract}

\section{KEYWORDS:}

Apocalypse, coded language, theology of history, interpretation.

\footnotetext{
* Docente Asociado de la Universidad Femenina del Sagrado Corazón: fgutierrez@unife.edu.pe
} 


\section{INTRODUCCIÓN:}

El último escrito del Nuevo Testamento ha suscitado variadas interpretaciones, ha dado lugar a movimientos milenaristas, a ver en él profecías sobre el fin del mundo, señales actuales que anuncian que llega el fin de los tiempos.

El Apocalipsis no pretende ser una revelación sobre el fin del mundo, sino una lectura de la historia a la luz de Dios, de las persecuciones de que son objeto los cristianos por parte de los romanos.

El mensaje del Apocalipsis es bastante claro para quien se acerca a él para encontrar fortaleza en momentos difíciles, cuando su fe parece tambalearse. Lo que nos parece casi incomprensible es que habiendo tantos comentarios serios que nos aproximan al mensaje de este último escrito, no obstante haya quienes lo lean al pie de la letra, viendo en él sólo descripciones de situaciones terroríficas que nos anuncian el fin del mundo.

A través de este estudio buscamos descubrir las claves de lectura de este escrito, para así tener una correcta interpretación del mensaje que el vidente de Patmos quiso dirigir a nuestras iglesias y a nuestra fe.

\section{El género literario apocalíptico ${ }^{1}$}

El Apocalipsis forma parte de un género literario caracterizado por una gran profusión de imágenes, alimentado por diez siglos de literatura judía o extranjera. Toma así mismo elementos de la época. Algunos de estos símbolos son aún transparentes; otros, por el contrario, son o parecen ser herméticos. Así un candelero rematado por una luz brillante en la noche sigue siendo una imagen actual; que una estrella pueda ser símbolo de una iglesia ya es menos familiar; pero un animal con diez cuernos llenos de ojos, es algo que puede ser considerado ya como un jeroglífico: por lo tanto se impone una explicación (Charlier: 1993).

Este género literario apocalíptico es bastante frecuente en la literatura judía, ya sea canónica o no canónica. En los escritos canónicos, su origen se remonta al libro de Ezequiel (593-571 aC.), pero es al libro de Daniel (167 aC.) al que se remontan la mayoría de los escritos apocalípticos judíos y cristianos.

En el AT encontramos este género en el "Gran Apocalipsis" de Is 24-27, y en la misma recopilación, el "Pequeño Apocalipsis" de los capítulos 34-35 (escritos tardíos, quizá contemporáneos a Daniel). En el NT lo encontramos en algunos pasajes de las cartas a los tesalonicenses y también en Mt 24 y paralelos.

En la literatura judía no canónica la mayoría de los escritos apocalípticos datan del s.I aC hasta el s. I dC. Esto pone de manifiesto la predilección del mundo judío por expresar sus sentimientos religiosos a través de este género, incluso en ambientes alejados del fariseísmo, como por ejemplo en Qumram². También en el cristianismo aparecieron muchos apocalipsis, pero la Iglesia no los

1 La palabra "apocalipsis" procede del griego y significa "revelación": "Toda apocalipsis supone, por lo tanto, una revelación de Dios a los hombres de cosas escondidas o sólo conocidas por Él" (Biblia de Jerusalén, introducción al libro del Apocalipsis).

2 Es significativa la semejanza entre el Apocalipsis de San Juan y el "Manuscrito de la Guerra" del Mar 
aceptó como inspirados, pues aún tuvo dificultades por aceptar este escrito como inspirado por su fuerte sabor judío ${ }^{3}$.

Este último escrito del NT constituye "el más bello tratado de teología que se pueda escribir con imágenes" (Charlier: 1993: 14). No es un escrito terrorífico y amenazador, sino lleno de alegría y esperanza. Cristo resucitado es el centro de la historia: el mundo es el escenario de la lucha entre la Iglesia, encabezada por Cristo, y las fuerzas del demonio. Los cristianos son llamados a dar valientemente su testimonio.

El estilo apocalíptico difiere notablemente del estilo de los otros escritos del NT, como es el caso de los evangelios, donde se presenta a un Jesús muy humano, muy cercano a los hombres y mujeres, sobre todo sencillos, un Jesús manso, que acoge a todos y perdona a los pecadores. El Jesús del Apocalipsis es un Cristo hierático presente en un mundo en delirio, un Cristo que, a primera vista, parece violento, vengador, atormentado. Otro rasgo importante del Apocalipsis es el marco urbano donde se desarrollan los acontecimientos descritos.

El Apocalipsis también difiere de las recopilaciones proféticas: el profeta oye una palabra y la transmite bajo la forma de un oráculo audible; el mensajero apocalíptico, en cambio, se considera un vidente y transmite su mensaje con la ayuda de cuadros vivos; el primero es incisivo, breve, el segundo es prolijo, difuso, con frecuencia confuso. A veces parece difícil reconocer si el Dios del Apocalipsis sigue siendo el mismo que el de los profetas.

\section{1 ¿Qué se persigue con este género?}

Estos escritos son compuestos en tiempos de crisis, de guerra, de persecuciones, de amenazas; están destinados a fortalecer la fe de los creyentes, a tener la convicción de que el mal no triunfará, sino el bien, Dios, Cristo; a tener esperanza de que vendrán tiempos mejores, a ser fieles al Dios de la Alianza, a resistir hasta el final por que el Cordero saldrá triunfante. Asî Daniel es escrito cuando los judíos eran perseguidos por los griegos, en tiempo de los Macabeos. Nuestro Apocalipsis es escrito cuando los cristianos de Asia eran perseguidos por los romanos; es escrito para fortalecer a estos cristianos que naturalmente se preguntaban si valía la pena sufrir por Cristo y que no sería mejor ofrecer incienso a los ídolos romanos y así escapar a las persecuciones.

"Los apocalipsis son manuales para resistentes, armados o no. Pretenden galvanizar las energías, tranquilizar al pueblo, indicarle la conducta a seguir. Están destinados a los guerrilleros de la fe, que desean levantarse contra las pruebas, sin saber demasiado cómo hacerlo, material o teológicamente" (Charlier: 1993: 15).

El apocalipsis era una forma de literatura muy de moda en tiempo de Jesús. Era un arte de escribir con imágenes muy grandiosas, visiones y ángeles sobre acontecimientos contemporáneos.

Rasgos de la literatura apocalíptica

a. La pseudonimia: Es evidente que estos escritos no están firmados,

\footnotetext{
Muerto. Ambos son escritos durante un período de persecuciones religiosas. En ambos encontramos una contraposición entre los hijos de la luz y los hijos de la oscuridad.

3 Hasta fines del s.II, las iglesias de Siria, de Capadocia y también la de Palestina no consideraban el Apocalipsis como un escrito canónico, señal de que no creían que fuera obra de un apóstol.
} 
sino que se acude a la pseudonimia, pues se identificaría a su autor y naturalmente sería perseguido e incluso asesinado. Por esta razón el autor del libro de Daniel no puede ser el profeta Daniel, como también el autor de nuestro Apocalipsis no puede ser Juan el Apóstol, quien, sin duda ya habría muerto hacía tiempo. Lo único que pretende es advertir a sus destinatarios que se inscribe en la línea teológica de la escuela joánica

b. La ficción del lugar: Al igual que el autor debe ser anónimo, así también era necesario que oculte su dirección. El lugar es ficticio: ni Daniel estaría ya en Babilonia ni Juan en Patmos. Por otra parte parece difícil que un exiliado político en esta isla hubiera podido gozar de tiempo libre para escribir una carta tan larga.

c. La ficción del tiempo: el autor de un escrito apocalíptico no precisa el tiempo, busca hacer pasar su escrito por un antiguo libro de enigmas sin interés. Daniel da la impresión de haber sido escrito en el 605 aC bajo Nabucodonosor, siendo patente por su lengua y contenido, que el libro fue escrito durante la rebelión macabea del año 167. De igual modo, el Apocalipsis busca hacer creer que fue escrito bajo Nerón, siendo que fue compuesto durante la persecución de Domiciano, hacia el año 96, cerca de cuarenta años más tarde.

d. La ficción del lenguaje: el lenguaje debe ser simbólico, codificado para que no sea comprensible para el enemigo, pero sí para sus destinatarios, para ello era necesario utilizar símbolos conocidos sólo por ellos. Para utilizar estos símbolos se tenía un gran recurso, el de las Escrituras.
El lenguaje codificado ofrece además la ventaja de universalizar e intemporalizar un mensaje concreto. Así al hablar simbólicamente de Babilonia para designar a Roma permitía universalizar el mensaje: si desapareciese Roma podría venir otra Roma, otra Babilonia en algún lugar del planeta.

Un lenguaje codificado, cifrado:

El lenguaje que utiliza el género apocalíptico es un lenguaje codificado, cifrado y que, por lo tanto, necesita ser decodificado, descifrado: "Es como una matemática simbólica, con la que se puede decir cualquier cosa, a menos que nos atengamos a algunas reglas precisas" (Charlier:1993:17).

Entra las cifras más útiles para comprender el apocalipsis tenemos: el número tres es la cifra del Dios invisible, que se comunica con los hombres a través de su Palabra, su Espíritu y su Sabiduría. El empleo de esta cifra se refiere a Dios en persona o todo lo que es divino, absoluto. Así renegar tres veces equivale a renegar de Dios en forma total, absoluta. Hacer una triple confesión de amor equivale a un arrepentimiento total, integral, definitivo.

El número cuatro, en cambio es símbolo de la creación, de los cuatro puntos cardinales que orientan el paisaje terrestre. Así en la Biblia se habla de los cuatro vientos, de los cuatro rincones de la tierra. Todo lo creado está significado por esta cifra.

De sumar o multiplicar el 3 y el 4 resulta el 7 ó el 12, que expresa la misma realidad: el encuentro íntimo del Creador con la creación, o sea la Alianza. Para expresar la intensidad, el éxito perfecto de la Alianza se elevará estas cifras, el 7 y el 12, al cuadrado resultando el 49 y 
el 144. Para expresar el carácter universal se multiplicará estos números por mil y obtendremos 49,000 y 144,000 (7,4-8: los 144,000 de Israel). Igualmente la ruptura de la alianza entre Dios y los hombres será simbolizada por la mitad de estos números, como si fueran partidos en dos. Así 31⁄2 y 6 son sinónimos de ruptura de la Alianza, de pecado, de crisis. También 3 1 1 2 podría tomar la forma de "un tiempo, 2 tiempos y la mitad de un tiempo", o también "42 meses" o incluso "1260 días" $(12,6)$.

Es necesario tener presente que el simbolismo del Apocalipsis es asombrosamente fluido y flexible, es decir que una misma realidad puede ser representada por diferentes símbolos: una iglesia puede ser representada ya sea por un candelero, una estrella, un ángel... y a la inversa, un mismo símbolo puede representar varias realidades: el pilocefalismo de las bestias puede significar o bien los reyes (cabezas coronadas), o bien imperios, o también colinas. Por lo tanto, el hecho de que un símbolo, en un versículo determinado signifique una realidad, no quiere decir que siempre signifique lo mismo.

\section{Estructura literaria del libro}

La estructura propuesta por muchos especialistas y que es propia del pensamiento semítico es la denominada estructura concéntrica, inclusión semítica o desarrollo en candelero.

Según este procedimiento inclusivo el momento fuerte se sitúa en el medio de la obra. Para expresar el núcleo del pensamiento, es dispuesto como una joya en su estuche. Para expresarlo el autor juega con una serie de correspondencias entre el comienzo y el final del libro. A este tipo de procedimiento se la conoce como "construcción en candelero", donde la primera rama está ligada orgánicamente a la última, la segunda a la penúltima, la tercera a la quinta, reservando una posición privilegiada a la cuarta. Este procedimiento se lo esquematiza de la manera siguiente: A-BC-D -C'-B'-A'. Tanto las palabras como las ideas establecen un vínculo entre $A$ y $A^{\prime}$, entre $\mathrm{B}$ y $\mathrm{B}^{\prime}$, entre $\mathrm{C}$ y $\mathrm{C}^{\prime}$, reservando a $\mathrm{D}$ un lugar preponderante. La lectura principal se realiza por la observación de las encajaduras.

Según este procedimiento el Apocalipsis tendría la siguiente estructura: un prólogo (0) seguido de cinco partes (A B C B' A') y terminando con una conclusión $\left(0^{\prime}\right)$.

En el Apocalipsis como en los evangelios encontramos grandes contrastes, contradicciones. No encontramos en él una luz, sin que se acentúe enseguida el contraste con las tinieblas. Así el Cordero está de pie, en postura de vencedor, pero ha sido muerto, degollado $(5,6)$. Cada sección, cada capítulo, casi cada versículo contiene estas contradicciones aparentes.

Todos los comentaristas están de acuerdo que el número 7 juega un papel importante en el apocalipsis, en él aparece 54 veces mientras que sólo 33 en el resto del NT. Según el simbolismo visto anteriormente, al autor habría querido decirnos que el Apocalipsis es el libro de la Alianza reanudada en Jesucristo, pero amenazada por las persecuciones que se ciernen sobre las iglesias. Este número 7 es, sin lugar a dudas, el que estructura todo el libro: siete iglesias, siete ángeles, siete sellos, siete truenos, siete trompetas. En unos casos se precisa el contenido del "septenario", como en los siete sellos, a los que se siguen una serie de detalles: tras la ruptura del primer sello, sucedió... En otros casos sólo se 
mencionan, sin dar demasiados detalles, como es el caso de los siete ángeles.

La estructura propuesta por Jean Pierre Charlier (1993:25) es:

0: Título y envío: 1,1-8

A: Primer septenario: las cartas a las siete iglesias: 1,9-4,11 B: Segundo septenario: los sellos: 5,1-8,1 C: Tercer septenario: las trompetas: $8,2-14,5$ B': Cuarto septenario: las copas: 14,6-19,8

A': Quinto septenario: las visiones: 19,9-22,5

0': Conclusión y saludo: 22,6-21.

\section{Los cinco símbolos mayores}

\section{a) Las siete cartas: primer septenario: 1,9-4,11}

Es el primero de los cinco grandes septenarios del Apocalipsis. En el NT aparecen tres tipos de cartas: la personal de un individuo a otro, como es la carta a Filemón; las comunitarias, como las de Pablo a las diferentes comunidades, que tratan problemáticas diversas de cada comunidad (epístolas) y las cartas que son pura ficción literaria.

En el caso del Apocalipsis todo indica que se trata de epístolas, pues están dirigidas a comunidades concretas: las siete iglesias del Asia Menor ${ }^{4}$ designadas por sus nombres respectivos. Estos siete documentos están encajados en un conjunto que se presenta todo él como una misiva (1,4-6), al estilo paulino. A partir del segundo septenario se presenta más bien como una ficción literaria. Los temas abordados en los otros cuatro capítulos desbordan las iglesias locales y se nos ofrece, más bien un tratado de eclesiología y de cristología.

Es a través de las siete iglesias del Asia que se dirige a la iglesia universal y eterna de Jesucristo. El verdadero autor es el Señor glorificado y su Espíritu Santo. Toda la iglesia que se encuentra aún en su condición terrestre es interpelada: su sentido, su razón de ser, su papel en la creación, su devenir, sus dificultades, sus angustias, sus lagunas... ese es el mensaje a las siete iglesias, con ejemplos tomados de situaciones concretas que son comunes a todas las iglesias de todos los tiempos.

\section{b) Los siete sellos: segundo septenario: $5,1-8,1$}

En oriente, todas las personas que detentan alguna notoriedad, poseen un sello grabado con su nombre o con su marca, para imprimir un signo de propiedad a todo lo que les pertenece: cosas, escritos, animales, hombres. El sello es algo tan personal que su propietario nunca se desprende de él, lo lleva colgado al cuello o como un anillo en el dedo.

En el Apocalipsis se trata de un documento sellado siete veces, es decir totalmente. El libro misterioso está redactado por el mismo Dios, los sellos garantizan su autenticidad. El escrito contiene el verdadero mensaje de Dios. El mensaje está destinado a toda la iglesia. Cristo, el Cordero, es el único capaz de abrir el libro y darnos a conocer su mensaje. A medida que se vayan rompiendo los sellos van a ser manifestados algunos fragmentos sueltos de este Apocalipsis (de esta revelación) e iremos conociendo, de manera cada vez más precisa, el objeto y después el contenido de esta acta auténtica de Dios.

En este septenario podemos encontrar tres series de elementos.

4 Las iglesias del Asia Menor eran más de siete, el número es simbólico designa una plenitud y las siete representan, pues, a todas las comunidades de cristianas (cfr. Biblia Latinoamericana, comentario al cap. 2). 
Primera, una garantía de victoria, luego un balance del mundo de siempre $y$, por último, una intervención y una manifestación de fe. Es una visión de la historia leída bajo la mirada de Dios, quien concede el poder al Cordero inmolado para abrir los sellos.

\section{c) Las siete trompetas: tercer septenario: 8,2 - 14,5}

Una trompeta es un instrumento de bronce que procede del arsenal militar; la señal de asalto, que sólo puede ser ordenada por el general que dirige la batalla. Provoca la reunión inmediata de las tropas bajo el estandarte, junto al cual se encuentra la corneta y permite evitar la confusión y el asalto dado por unidades desprovistas de organización. La trompeta es provocación y convocación, transmite una orden y una misión de ataque.

Existe una relación entre el simbolismo de los sellos y el de las trompetas. Los sellos conducen al conocimiento, en cambio las trompetas deciden sobre una acción poderosa. Dios ha transmitido su conocimiento mistérico de la historia al Cordero; en cuanto éste ha sido revestido de esta prerrogativa, las trompetas pueden entonar el canto de las acciones sucesivas, que permitirán una feliz realización de los secretos contenidos en el rollo cerrado.

\section{d) Las siete copas: cuarto septenario: 14,6-19,8}

La copa, en la cultura judía, era un recipiente en el cual el jefe de casa vierte el líquido para que beban sus convidados, simbolizando así una alianza estrecha y fuerte entre los comensales (1 Cor $11,25)$. La copa es, por lo tanto, símbolo de alianza y comunión, de compartir una alegría común evocada y provocada por el vino que contiene.
La copa de este septenario es el símbolo de la des-comunión con Dios y, por consiguiente, de la cólera divina. Una correcta lectura de estos símbolos no es una descripción anticipada del fin del mundo, sino un fracaso radical de los imperios que hayan querido reemplazar la autoridad y el poder de Dios por los suyos propios. El tiempo de estos imperios está contado y debe establecerse un orden diferente, de lo cual se ocupará el quinto septenario.

\section{e) Las siete visiones: Quinto septenario: 19,9-22,5}

El Dios de la Biblia es un Dios que habla y el creyente es aquel que escucha. Hablar y escuchar son dos verbos que se corresponden. Escuchar no es sólo disponer el oído, sino también el corazón, la inteligencia, pues se trata de comprender y de interpretar con discernimiento. Escuchar no es un acto pasivo, sino inserción de lo que se escucha en la vida y en el comportamiento.

Las visiones nos conducen hacia la Jerusalén nueva, la ciudad esposa, donde nos espera el Cordero.

\section{Una teología de la historia.}

\subsection{El Imperio Romano y la Iglesia}

El Imperio Romano es descrito como "el dragón rojo con siete cabezas y diez cuernos y en las cabezas siete coronas" $(12,1)$. Éste persigue a la iglesia de Cristo que es simbolizada por la mujer que está por dar a luz un hijo varón, que es el fruto de la iglesia, los cristianos.

La mujer que está embarazada y grita de dolor porque va a dar a luz es la Iglesia que sufre las persecuciones, que huye al desierto, pero que es alimentada por la palabra de Dios $(12,6)$. 
El Emperador es descrito como la bestia que tiene siete cabezas y diez cuernos, con diez coronas en los cuernos y en las cabezas un título que ofende a Dios $(13,1)$. El poder político, con el emperador a la cabeza, busca convencer a los hombres de que no es Cristo el dueño del mundo en que vivimos. Si desean vivir, tienen que entregar su libertad y su conciencia a otro señor, el poder político.

Cuando es escrito el Apocalipsis el Emperador Domiciano acababa de imponer a todos sus súbditos la obligación de honrarlo como un dios. En esta situación los cristianos tenían que hacer una elección tremenda: al confesar a Cristo, Señor de la vida, enfrentaban persecuciones. Juan Señala el deber de permanecer fiel a Cristo y negarse a dar culto al César. Un grupo de cristianos se enfrentará al estado totalitario: la Iglesia vencerá por la sangre de los mártires.

Las dos bestias representan los dos poderes (el político y el religioso), que unen sus fuerzas al servicio del dragón, contra la Iglesia. La bestia que se parecía a un leopardo $(13,2)$, representa el poder perseguidor, el del Imperio Romano; viene del mar, o sea del occidente, de Roma. La otra bestia $(13,11)$ sale del continente o sea del este, de Asia y figura las religiones que competían contra el cristianismo. Estas pretendían dar una salvación celestial, pero no condenaban los pecados del mundo romano. Estas religiones eran utilizadas por el poder político. Los que pertenecían al Imperio tenían una contraseña para poder comprar o vender productos: "nadie podía comprar o vender sino está marcado con el nombre de la bestia o con la cifra de su nombre" $(13,7)$. Por ello, para un cristiano era difícil acceder a la compra o venta de productos. La cifra de la bestia era el 666: para muchos se refería al Emperador Nerón, que pretendió ser siete pero no lo logró. "El Cordero estaba de pie sobre el Monte Sión" (14,1): Sión es la Iglesia, tanto celestial como terrenal. Los 144,000 $(14,1)$ designan a los cristianos del Imperio Romano, así como los 144,000 de 7,4-9 designaban a los elegidos de raza judía.

En 15,1 se anuncia la caída del Imperio Romano, que es esperada y considerada como un juicio de Dios.

\subsection{Roma}

Es denominada como Babilonia, como la gran prostituta $(17,1)$ : para todos los que vivían en el Imperio Roma era la personificación del Imperio Romano y de su cultura. Al llegar a la capital los visitantes quedaban deslumbrados por sus edificios, sus templos, sus teatros, sus luces, su población incontable. Y no les costaba venerar a Roma como a una divinidad.

La duración del Imperio, visto como invencible y divino es puro engaño: "era, no es y pasa pronto" $(17,8)$, a diferencia de Dios que es y ha de venir. Juan figura a Roma como una mujer endemoniada. El púrpura, color de los emperadores, y el oro, signo de su riqueza, tapan sus impurezas y su crueldad. Es al mismo tiempo la que lleva a los hombres a servir a divinidades falsas y la que asesina a los mártires.

Juan habla del futuro cercano de Roma, usando símbolos: las siete colinas designan sin duda a Roma. Los siete reyes son una cifra simbólica de emperadores. Los diez cuernos son los reyes de los pueblos bárbaros aliados de Roma. Estos satélites serán los instrumentos de Dios para destruirla, pero seguirán siendo hostiles a la Iglesia. 
En el anfiteatro Flavio o Coliseo Romano los romanos disfrutaban viendo que las fieras salvajes devoraban a los cristianos:"En su frente se podía leer su nombre, escrito en forma cifrada: Babilonia la Grande, la madre de las prostitutas y de los abominables ídolos del mundo entero. Y observé que la mujer se había embriagado con la sangre de los santos y de los mártires de Jesús" $(17,5-6)$.

\subsection{Enseñanzas teológicas}

El Apocalipsis no es una simple visión de la historia, de los acontecimientos puntuales del Imperio Romano de finales del s.I, ni tampoco una revelación del futuro, del fin de los tiempos. Es más bien una reflexión teológica sobre la Iglesia que sufre persecuciones por parte de los romanos, pero que también busca dejarnos un mensaje válido para todos los tiempos: es necesario resistir a la tentación, el mal no va a triunfar, sino Cristo, el Cordero degollado y ahora triunfante.

Las cinco grandes partes del Apocalipsis nos llevan a cinco grandes reflexiones, siguiendo el orden de los septenarios:

a. Todo comienza por la Iglesia: la obra fue escrita para comunidades cristianas en peligro. Por ello, el mensaje que dirige a cada iglesia es directo, personal, preciso. Se trata de la Iglesia de Jesucristo ejemplarizada en las siete comunidades del Asia. Esta Iglesia fue preparada por Israel. Esta teología hunde sus raíces en la Escritura para quien el acontecimiento decisivo es Israel. Para el Apocalipsis la elección de Dios de Israel culmina en la Iglesia, que es la que da sentido al mundo. b. En el segundo septenario nos da una visión del mundo, o creación o historia. En este mundo lleno de imperfecciones, de tibiezas y de pecado, está presente la Iglesia; en él reinan permanentemente conflictos de toda clase, le acechan múltiples males. El Cordero abre los sellos: Cristo resucitado es quien aclara las grandes fuerzas que impulsaron la historia sagrada. En el momento que se escribe el Apocalipsis ya se había terminado el AT por el nacimiento de la Iglesia y poco después, por la destrucción de la patria judía. Los cuatro caballos simbolizan las fuerzan que han plasmado la historia bíblica: el que monta el caballo blanco es "la palabra de Dios" que él había entregado a los profetas en el AT. Todavía no había venido Cristo que aparecerá más tarde montado en el mismo caballo blanco, cuando ya estamos en la historia cristiana $(19,11)$. Los otros tres caballos representan la guerra, el hambre y las epidemias, las grandes plagas que aquejan a la humanidad pecadora, y que hacen sentir a los hombres que necesitan de salvación. Con el quinto sello se descubre otra fuerza invisible que mueve la historia sagrada: la exigencia de justicia por la sangre de los mártires. Estos mártires anteriores a Cristo ya comparten su victoria (por eso el vestido blanco), pero deben esperar a que se junten con ellos los mártires cristianos. Con el sexto sello aparecen los signos y las plagas que los profetas anunciaban para el Día de Yavé y que se verificaron en la destrucción de Jerusalén. "Cuando el Cordero abrió el séptimo sello" nos quiere decir 
que estamos a fines del AT y el silencio que se produce anuncia la venida de Dios 5 .

c. Las siete trompetas, tercer septenario, pretenden mostrar el castigo del pueblo judío que no recibió a Cristo; usan figuras sacadas de las plagas de Egipto, de Ez 38-39 y de otros escritos populares. Con las cuatro primeras trompetas el castigo toma cuerpo en las mismas fuerzas de la naturaleza que se vuelven contra los culpables. La tercera hace caer del cielo a la tierra las fuerzas maléficas del demonio. La quinta puede referirse a invasiones extranjeras. Esta parte es una de las que más atraen la curiosidad y que han dado lugar a interpretar el Apocalipsis como referido a una serie de calamidades mundiales que anuncian el fin del mundo 6 .

d. El cuarto septenario, las siete copas, no anuncia para nada el fin del mundo, sino que denuncia los peligros mortales que anidan en los imperios y describe, de manera simbólica, la caída de los que hayan vuelto la espalda a las bienaventuranzas evangélicas. El capítulo de las copas no es otra cosa que una amplia parábola sobre el fracaso de las empresas humanas, cuando éstas desprecian la presencia y el reinado de Dios.

e. El último septenario, las siete visiones, nos expresan lo que será de aquellos que siguen el plan evangélico. Todo será embellecido en un marco nuevo, donde Dios ya no será puesto en cuestión. Será reconocido con un amor total y gratuito. Con la Jerusalénesposa, tanto la primera creación como la Iglesia terrestre llegarán a su acabamiento: en adelante pertenecerán a otro orden, habrá un nuevo cielo y una nueva tierra, el sol yo no será necesario para vivir con claridad; todo será renovado.

\subsection{Plan de encajaduras}

Para resaltar el aspecto teológico, J.P. Charlier propone el siguiente esquema (1993:36-39):

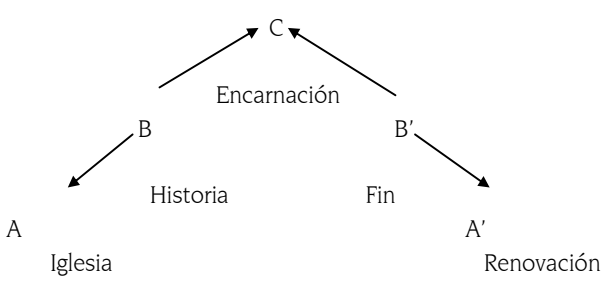

Este plan pone de relieve el momento central y preferencial de la Encarnación, que se constituye el primero en la construcción literaria. Con relación a esta cumbre A y B están en el mismo lado y B' y A' en la otra vertiente. C influye por una parte en A y B y, por otra, en B' y A'. Por último, B tiene incidencia sobre A y, por otra, B' sobre A'.

Los elementos A y B, con toda evidencia, se sitúan en el plano histórico: la Iglesia y el mundo pertenecen al curso de nuestra historia. De otra parte B' y A' se sitúan en el plano no histórico, salvífico, de lo incognoscible: no resulta válido utilizar estos últimos para referirlos al futuro. En esta perspectiva C no ocupa una posición intermedia, sino totalizadora. Forma parte tanto de

5 Biblia Latinoamericana, comentario a la sección de los siete sellos.

6 Es el centro del Libro y encontramos en él los tres grandes ejes de la historia cristiana: capítulos 10.12:

- El secreto de Dios revelado, Dios hecho hombre: cap. 10

- El Evangelio proclamado: cap. 11

- La rebeldía contra el plan de Dios: cap. 12 
la historia como de la no historia. Es un punto de fusión y encuentro de la tierra (lugar-espacio de los hombres) y el cielo (no-espacio y no-lugar de Dios). La Encarnación se convierte así en la adición de lo terrestre (4) y de lo celeste (3): es 7, la Alianza. Por otro lado, por el lugar que ocupa en la estructura, la Encarnación aparece como el resultado conjunto del trabajo de los hombres (A y B) y el don gratuito de Dios (B' y A'). Se capta aún que hay cielo en $A$, como esperanza y tierra en $A^{\prime}$ como recuerdo.

\section{CONCLUSIÓN:}

Para comprender el Apocalipsis es necesario conocer el momento histórico en que es escrito: las persecuciones de que son víctimas los cristianos por parte de los romanos, expresado en el género apocalíptico muy utilizado en la literatura judía de entonces, ya sea canónica o extracanónica.

Este escrito no tuvo como finalidad hablarnos del fin del mundo, no son profecías sobre el futuro, sino una teología de la historia: fortalecer a los cristianos perseguidos para que se mantengan fieles a Cristo y no renieguen de su fe.

Encontramos en el Apocalipsis un mensaje perenne, válido también para nosotros cristianos del s.XXI, que hemos decidido seguir a Cristo y debemos mantenernos fieles a él en medio de las dificultades que nos presenta la modernidad y postmodernidad, cuando Dios es suplantado por otros ídolos como el poder, el dinero, la fama, que no pueden darnos la salvación, sino sólo Cristo.

\section{REFERENCIAS:}

CASTELLAN, L. (2005) El Apocalipsis de San Juan. Buenos Aires: Vórtice.

CHARLIER, J. P. (1993) Comprender el Apocalipsis. Bilbao, Descleé de Brower.

GARCÍA CORDERO, M. (1962) El libro de los 7 sellos (exposición exegéticoteológica del apocalipsis). Salamanca: San Esteban.

HAH, S. (2001)La Cena del Cordero: La Misa, el cielo en la tierra. Madrid, Ediciones Rialp.

LÄPPLE, A. (1970) L'Apocalypse de Jean: livre de vie pour le chretiens. París: Éditions du Cerf.

VANNI, U. (1971)La struttura letteraria dell'Apocalisse. Roma: Herder.

VANNI, U. (1982) Apocalipsis: una asamblea litúrgica interpreta la historia. Navarra: Verbo Divino. 